\title{
Governmental or Social Support of Bariatric Surgery in the Asia-Pacific Region
}

\author{
Jisun Lim ${ }^{1,+}$, Young Hye Cho ${ }^{2,+}$, Hiroshi Yamamoto ${ }^{3}$, Alvin Eng ${ }^{4}$, Tania Markovic ${ }^{5}$ Kyoung Kon Kim ${ }^{6, *}$ \\ ${ }^{1}$ Department of Family Medicine, Asan Medical Center, University of Ulsan College of Medicine, Seoul; ${ }^{2}$ Department of Family Medicine, Pusan National University \\ Yangsan Hospital, Yangsan, Korea: ${ }^{3}$ Department of Surgery, Kusatsu General Hospital, Japan; ${ }^{4}$ MIS \& Bariatric Surgery, Singapore General Hospital, Singapore; \\ ${ }^{5}$ Metabolism Et Obesity Services, Royal Prince Alfred Hospital, Boden Institute, University of Sydney, Australia; ${ }^{6}$ Department of Family Medicine, Gachon University \\ Gil Medical Center, Incheon, Korea
}

Herein we review the management status of governmental financial support of bariatric surgeries in several Asia-Pacific areas of Japan, Singapore, and Australia, which were discussed in the 2016 International Congress on Obesity and Metabolic Syndrome (ICOMES). Patient's body mass index criteria of bariatric surgery for public support are different one another in the three countries. Whereas laparoscopic sleeve gastrectomy (LSG), Rouxen Y gastric bypass (RYGB), and laparoscopic adjustable gastric banding (LAGB) are applicable in both Singapore and Australia, the coverage of insurance is limited to LSG in Japan. In addition, the surgical fees and equipment costs are not fully covered by public health insurance for performing sleeve gastrectomy in Japan, but patients with morbid obesity can still use public health insurance. In Singapore, the waiting time for surgery in public hospitals is longer on average than for private hospitals. However, patients can obtain subsidies of up to $80 \%$ of the costs of surgery in public hospitals, while particularly needy patients may even be able to obtain completely free bariatric surgery through Medifund. In Australia, bariatric surgeries in public sectors are publicly funded, but most bariatric surgeries occur in the private sector and Medicare only reimburses surgical costs in the private sector. Although certain characteristics need to be improved, the access to bariatric surgery has shown steady progress through public support in each of these countries.

Key words: Bariatric surgery, Morbid obesity, Social support
Received December 12, 2016

Reviewed January 17, 2017

Accepted February 20, 2017

${ }^{*}$ Corresponding author

Kyoung Kon Kim

(iD)

http://orcid.org/0000-0003-0374-2571

Department of Family Medicine, Gachon University Gil Hospital, 21 Namdongdaero 774beon-gil, Namdong-gu, Incheon 21565, Korea

Tel: +82-32-460-2735

Fax: +82-32-460-3354

E-mail:zaduplum@aim.com

tThese two co-first authors contributed equally to this work.

\section{INTRODUCTION}

Nowadays, bariatric surgery is of great clinical importance in Korea. The prevalence of morbid obesity has markedly increased from 2002 to 2013, especially in young adults in their thirties and forties. Recently, the number of obese people with diabetes has also rapidly increased. ${ }^{1}$ Bariatric surgeries have been shown to have the greatest efficacy in treating morbid obesity, resulting in many patients with diabetes achieving good glycemic control without the need for glu- cose-lowering medications. ${ }^{2,3}$ Thus, particularly for patients who are obese and who have diabetes, bariatric surgery should be considered as an important treatment in Korea.

One of largest barriers to bariatric surgery is the cost. Obesity, especially morbid obesity, is more prominent in individuals from a lower socioeconomic background in Korea. Fortunately, the Korean National Health Insurance Service is reviewing insurance coverage for bariatric surgery. In the Asia-Pacific region, there are governmental or social financial support systems for bariatric surgery in

Copyright (C) 2017 Korean Society for the Study of Obesity

(a) This is an Open Access article distributed under the terms of the Creative Commons Attribution Non-Commercial License (http://creativecommons.org/licenses/by-nc/4.0/) which permits unrestricted non-commercial use, distribution, and reproduction in any medium, provided the original work is properly cited. 
Japan, Singapore, and Australia, and in this article, we will review the various systems used in these countries.

\section{Health insurance coverage for bariatric surgery in Japan}

There are two types of public health insurance in Japan. ${ }^{4}$ One is Social Insurance (or Employee's Health Insurance), which is used by individuals working for a company. The other is National Health Insurance, which is used by those who are not covered by Social Insurance. With support from these two public health insurances, almost all residents in Japan receive a high level of medical services.

In 2016, laparoscopic sleeve gastrectomy (LSG) was the only bariatric surgery procedure that was financially supported by health insurance. Generally speaking for insurance coverage, any given medical treatment should be approved by the national council. In the case of an approved treatment, patients are supposed to pay $30 \%$ of the medical fees when they are treated. Newly developed medical technologies should be approved by the Advanced Medical Technology System in place in Japan in order to be covered by insurance. ${ }^{5}$ In 2010, LSG was approved by Advanced Medical Technology, and after that, LSG was listed as being covered by public health insurance in 2014, which contributed to the increased number of LSG surgeries in Japan. However, other bariatric surgery methods have not been approved nor covered by health insurance. Bypass surgeries are not covered by public health insurance, but they can be performed in some private hospitals.

Even though the number of facilities performing bariatric surgery has increased, the accessibility was still not good enough in 2016 in Japan. At present, there are only twenty facilities performing bariatric surgery. The number of bariatric surgeries performed in 2015 was 258 . There are several reasons why the numbers of facilities performing bariatric surgery and of bariatric surgeries themselves did not increase under public health insurance coverage. First, the amount of money available through health insurance is not enough to perform LSG surgeries. Although the surgical fees were paid, the costs of surgical equipment, trocars, and staplers were not covered by public health insurance. Therefore, LSG resulted in a deficit for many hospitals when such surgeries were performed. In 2016, the surgical fees increased and five staplers were covered for LSG by insurance. Second, the criteria for facility approval are very strict. The criteria include: that the number of laparoscopic gastric surgeries should be more than 20 cases per year; surgeons should have more than five years of experience in general surgery; surgeons should have more than ten cases of experience with LSG as an operator; there should be physicians with more than five years of experience with treatments for diabetes, hypertension and hyperlipidemia; and full-time employed anesthesiologists and registered dietitians are mandatory. Third, the patient selection criteria are also strict. The body mass index (BMI) of patients should be greater than or equal to $35 \mathrm{~kg} / \mathrm{m}^{2}$ with at least one obesity-related comorbidity and the patient should have had an at least six-month medical treatment that did not work. While the Japanese system may guarantee the quality of the surgery, it may also work as a barrier to the bariatric surgeries. In conclusion, LSG is the only procedure covered by the public health insurance, and both the facility approval and the patient selection system are very strict in Japan.

\section{Healthcare system for bariatric surgery in Singapore}

Singapore has an efficient healthcare system in which the government ensures affordability through a subsidy system and where bariatric surgery is supported by the system, provided they fulfill certain BMI and comorbidity criteria in the Ministry of Health guidelines on obesity. All the Singaporeans who are treated in public hospitals can obtain healthcare subsidies in Singapore. The criteria for getting bariatric surgery in Singapore are obese patients with a BMI $\geq 37.5 \mathrm{~kg} / \mathrm{m}^{2}$ or a BMI $\geq 32.5 \mathrm{~kg} / \mathrm{m}^{2}$ with medical comorbidities of obesity. This follows the World Health Organization (WHO) expert consultation on BMI in Asian populations, which met in Singapore in 2002. ${ }^{6}$ The supported bariatric surgery procedures are laparoscopic adjustable gastric banding (LAGB), Rouxen-Y gastric bypass (RYGB), and sleeve gastrectomy (SG). The public hospitals' ward classes are classified into A, B, and C. $81 \%$ of the public hospitals' beds of class B2 (5 or 6-bedded room) and class $\mathrm{C}$ (9-bedded room) are heavily subsidized by the remaining $19 \%$ with lower subsidies at 20\% for class B1 (4-bedded room) and no subsidy for A class wards (single room); note that this is the same for bariatric surgeries as well. In some cases, government subsidies may even cover abdominoplasty after the weight loss induced by bariatric surgery. The waiting time for surgery on a regular weekday operating list is on the order of months at public hospitals. Although patients at private hospitals receive no subsidies from the 
Ministry of Health, they have the advantages of very fast appointments and investigations before surgery. Preoperative workups in private hospitals usually take a couple of days, and the waiting time for surgery is usually less than two weeks. The costs of bariatric surgeries at private hospitals are about three times higher than the costs at public hospitals.

Another main factor of the Singapore healthcare system is that it is a system of compulsory savings, and bariatric surgery can be supported through such a system. The Central Provident Fund (CPF) in Singapore is a compulsory savings plan that requires all employers and employees to contribute a portion of the employee's monthly gross salary to the provident fund, the main purpose being to provide retirement income. Among the CPF account, Medisave accounts directly pay for medical bills and can also be used to purchase medical insurance such as Medishield, which is administered by the CPF Board. Medishield pays for bariatric surgery but is pegged at Class B2/C wards. Medifund is an endowment fund set up by the government to help needy Singaporeans who face financial difficulties with their remaining bills after receiving government subsidies and drawing on other means of payments, including MediShield Life, private insurances, Medisave and cash. By using Medifund, obese patients with severe diabetes complications can receive bariatric surgery even if they are very poor.

In short, bariatric surgery is supported by government subsidies and compulsory savings in public hospitals.

\section{Private and public sectors of the healthcare system for}

\section{bariatric surgery in Australia}

The Australian health care system is composed of private and government sectors. 'Medicare' is administered by the federal government and is Australia's publicly funded (i.e., through taxes) universal health care system. Medicare subsidizes bariatric surgery and postsurgical care in the private sector, but the rebate is low (AUS\$637-784, depending on the procedure). Bariatric surgeries in the public sector are publicly funded.

Most bariatric surgeries occur in private hospitals with large outof-pocket expenses ${ }^{7}$, so the individuals most in need of surgery have the worst access to it. In Australia in 2007-2008, only 958 bariatric operations were performed in public patients, whereas 13,974 surgeries were performed in patients with private health insurance and 1,823 surgeries in self-funded patients. ${ }^{8}$ The most popular procedure is SG, and based on the Medicare items processed from July 2015 to June 2016, there were 13,681 SG cases, 2,199 LAGB cases, and 1,990 RYGB cases.

There are differences in the criteria for patient selection and follow up after surgery between the private and public sectors. In Australia, the Bariatric Surgery Registry (BSR) monitors the outcomes for patients who undergo bariatric surgery performed in the public and private sectors. 168 surgeons have registered an interest in bariatric surgery with the BSR, and to date 94 surgeons are contributing to the registry. The mean BMI of patients who had bariatric surgery with private insurance was $43.2 \mathrm{~kg} / \mathrm{m}^{2}$, whereas the mean BMI of those who had surgery in the public system was $49.3 \mathrm{~kg} /$ $\mathrm{m}^{2}$. In the private sector, patients usually initially contacted the surgeon who referred the patient to a physician pre-operatively for assessment if deemed necessary. Surgery is usually booked within weeks of initial contact at a time convenient for the patients. Body contouring surgery is also readily available in the private sector. In the public sector, patients with a BMI greater than or equal to 35 $\mathrm{kg} / \mathrm{m}^{2}$ with comorbidities or patients with a BMI above $40 \mathrm{~kg} / \mathrm{m}^{2}$ can be considered for bariatric surgery, usually going on a waiting list and having surgery at a later date. The availability of body contouring surgeries in the public system is very limited. Patient selection and follow up after surgery are generally more stringent in the public sector.

\section{CONCLUSION}

Table 1, Figs. 1 and 2 show summaries of the characteristics of governmental social supports for bariatric surgery in three countries. The patient criteria of bariatric surgery for public supports are somewhat different between each country (Fig. 1). Whereas the main surgical methods in Singapore and Australia are SG, RYGB, and gastric banding, the coverage of insurance is limited to SG in Japan (Fig. 2 ). In addition, the surgical fees and equipment costs are not fully covered by public health insurance for performing sleeve gastrectomy, and the facility criteria and patient criteria are also somewhat strict in Japan. However, the development of bariatric surgery in Japan has been making steady progress within the public health insurance system. In Singapore, the waiting time for surgery in public hos- 
Table 1. The characteristics of governmental social support of bariatric surgery in each country

\begin{tabular}{|c|c|c|c|}
\hline & Japan & Singapore & Australia \\
\hline Advantages & $\begin{array}{l}\text { Obesity patients can obtain public health insurance } \\
\text { Development of bariatric surgery has made steady } \\
\text { progress within public health insurance }\end{array}$ & $\begin{array}{l}\text { Patients can get subsidies of up to } 80 \% \text { of the costs of } \\
\text { surgery in public hospitals } \\
\text { Through Medifund, particularly needy patients can have } \\
\text { completely free bariatric surgery } \\
\text { Abdominoplasties can be subsidized by the government }\end{array}$ & $\begin{array}{l}\text { Medicare subsidies bariatric surgery and postsurgical } \\
\text { cares in private sectors } \\
\text { Bariatric surgeries in public sectors are publicly funded }\end{array}$ \\
\hline Disadvantages & $\begin{array}{l}\text { The coverage of insurance is limited to SG } \\
\text { Surgical fees and equipment costs are not fully covered } \\
\text { by public health insurance for performing LSG } \\
\text { The facility criteria and patient criteria are strict }\end{array}$ & $\begin{array}{l}\text { The waiting time for surgery in public hospitals is longer } \\
\text { than in private hospitals } \\
\text { Patients at an A class public hospital cannot receive } \\
\text { government subsidies } \\
\text { Patients at private hospitals receive no subsidies from } \\
\text { the government }\end{array}$ & $\begin{array}{l}\text { Medicare only reimburses surgical costs in private } \\
\text { sectors } \\
\text { The use of bariatric surgery in public sectors is limited } \\
\text { The availability of body contouring surgeries in public } \\
\text { sectors is very limited }\end{array}$ \\
\hline
\end{tabular}

SG, sleeve gastrectomy; RYGB, roux-en Y gastric bypass; LSG, laparoscopic sleeve gastrectomy.
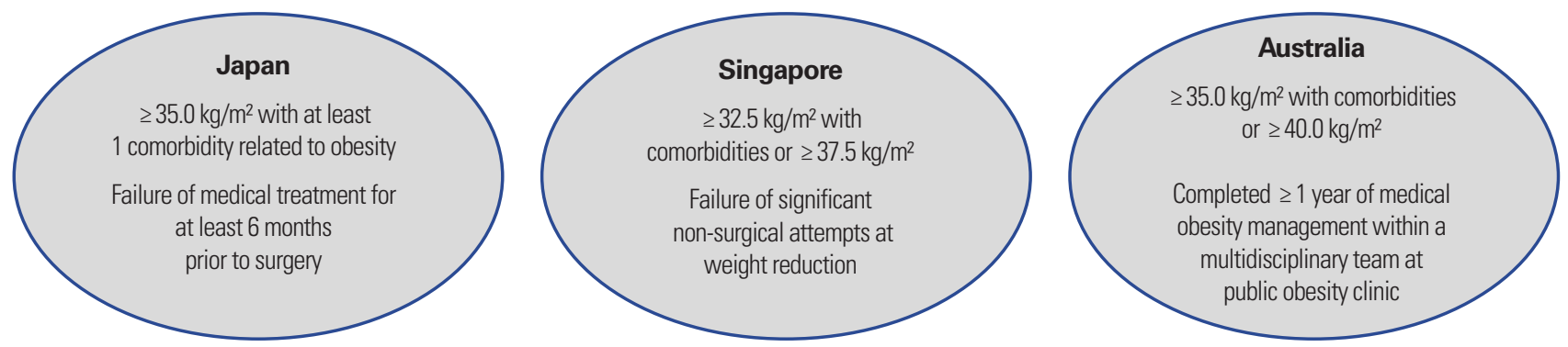

Figure 1. Patient criteria of bariatric surgery for public support.
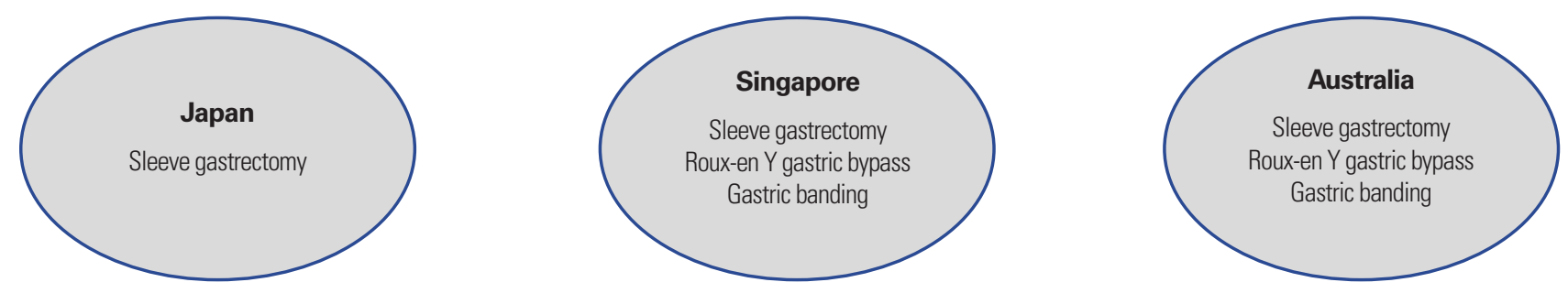

Figure 2. Applicable surgical method.

pitals is longer than for private hospitals. However, patients can get subsidies of up to $80 \%$ of the cost of surgery in public hospitals, and some particularly needy patients can even receive additional financial assistance for bariatric surgery through Medifund. In Australia, bariatric surgeries in the public sector are publicly funded. However, most bariatric surgeries occur in the private sector and Medicare only reimburses surgical costs in the private sectors (Table 1).

Although some conditions still need to be improved, bariatric surgery has shown steady progress within public supports in each of the countries listed above. In Korea, bariatric surgery should be available through governmental public support, which could result in savings of health expenditures due to obesity. This review could help with the effective implementation of coverage expansion for social insur- ance benefits, specifically the costs of bariatric surgery.

\section{CONFLICTS OF INTEREST}

The authors declare no conflicts of interest.

\section{ACKNOWLEDGMENTS}

J.L. and Y.H.C. wrote the draft of the manuscript and contributed equally to this work. H.Y., A.E., and T.M. gave presentations about the governmental social support of bariatric surgery in their respective countries in 2016 ICOMES. K.K.K. reviewed and edited the manuscript. 


\section{REFERENCES}

1. Ha KH, Kim DJ. Trends in the diabetes epidemic in Korea. Endocrinol Metab (Seoul) 2015;30:142-6.

2. DeMaria EJ. Bariatric surgery for morbid obesity. N Engl J Med 2007;356:2176-83.

3. Schauer PR, Kashyap SR, Wolski K, Brethauer SA, Kirwan JP, Pothier CE, et al. Bariatric surgery versus intensive medical therapy in obese patients with diabetes. N Engl J Med 2012; 366:1567-76.

4. Fukawa T. Public Health Insurance in Japan. 1st ed. Washington, DC: The International Bank for Reconstruction and Development/The World Bank; 2002.

5. Sakurai H. Advanced medical technology and health insurance in Japan. Japan Med Assoc J 2006;49:41-3.

6. WHO Expert Consultation. Appropriate body-mass index for Asian populations and its implications for policy and interven- tion strategies. Lancet 2004;363:157-63.

7. Korda RJ, Joshy G, Jorm LR, Butler JR, Banks E. Inequalities in bariatric surgery in Australia: findings from 49,364 obese participants in a prospective cohort study. Med J Aust 2012; 197:631-6.

8. Australian Institute of Health and Welfare. Weight loss surgery in Australia. Canberra: Australian Government, Australian Instittute of Health and Welfare; 2010. Available from: URL: http://www.aihw.gov.au/WorkArea/DownloadAsset.aspx?id= 6442472773

9. Bariatric surgery registry. Fourth report of the bariatric surgery registry v2. School of public health and preventive medicine Monash University, Obesity Surgery Society of Australia \& New Zealand; 2016. Available from: URL: http://www.med. monash.edu.au/sphpm/depts-centres-units/bariatric/docs/ bsr-4th-report-june-2016.pdf 